Web Jurnal:

http://ejournal.kemenperin.go.id/jli

\title{
Mempelajari inhibisi korosi senyawa khellin dan visnagin pada atom besi menggunakan metode DFT (density functional theory)
}

\section{Study on corrosion inhibition of khellin and visnagin compounds in iron using DFT (density functional theory) method}

\author{
Lidia Gusfi Marni $^{1}$, Emriadi $^{1} *$, Syukri $^{2}$, Imelda $^{1}$ \\ Laboratorium Kimia Komputasi Jurusan Kimia, Fakultas Matematika dan Ilmu pengetahuan \\ Alam, Universitas Andalas, Kampus Limau Manis Padang 25163, Indonesia \\ 2 Laboratorium Kimia Material Jurusan Kimia, Fakultas Matematika dan Ilmu pengetahuan Alam, \\ Universitas Andalas, Kampus Limau Manis Padang 25163, Indonesia \\ * e-mail: emriadi@sci.unand.ac.id
}

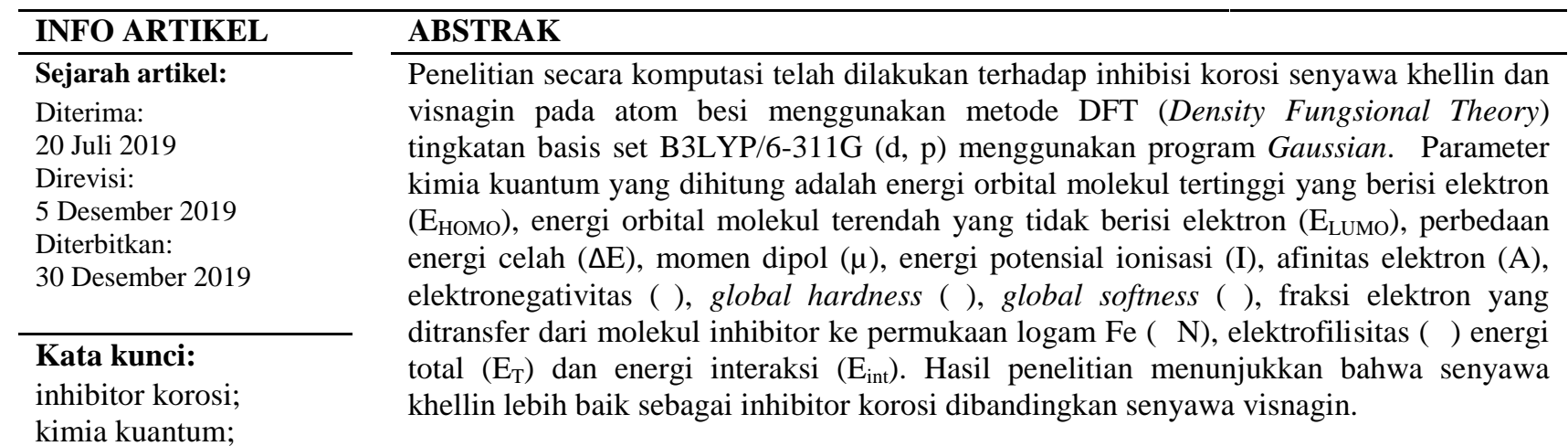

DFT;

khellin;

visnagin

Keywords:

corrosion inhibitor; quantum chemical;

DFT;

khellin;

visnagin

\begin{abstract}
Computational research has been investigated on inhibition corrosion of khellin and visnagin compounds on iron using DFT (Functional Density Theory) method in the base set B3LYP / 6-311G $(d, p)$ with Gaussian software. The quantum chemical parameters are the highest occupied molecular orbital energy $\left(\mathrm{E}_{\text {номо }}\right)$, the lowest unoccupied molecular orbital energy $\left(\mathrm{E}_{L U M O}\right)$, energy gap $(E)$, dipole moment $(\mu)$, ionization potential (I), electron affinity (A), the electronegativity ( $\chi$ ), global hardness ( $\eta)$, global softness $(\sigma)$, the fractions of electrons transferred from inhibitor to $\mathrm{Fe}(\mathrm{N})$, electropilicity index $(\omega)$ total energy $\left(E_{T}\right)$ and the interaction energy (Eint). The results show that khellin to protect the corrosion of iron have a higher inhibitory potential compared to visnagin compound.
\end{abstract}

\section{Pendahuluan}

Perkembangan teknologi komputer saat ini dapat digunakan untuk perhitungan kimia kuantum, dimana dengan perhitungan ini dapat diprediksi sifat-sifat suatu senyawa dengan hasil yang akurat (Fiolhais et al., 2003). Hal inilah yang menjadi dasar lahirnya kimia komputasi (Prianto, 2007). Salah satu metode yang banyak digunakan untuk perhitungan secara komputasi adalah metode Density Functional Theory (DFT).
DFT merupakan metode perhitungan kimia dengan penyelesaian persamaan Schrodinger secara sederhana, karena didasarkan pada perhitungan densitas elektron (Comba et al., 2001). Pada metode ini energi suatu molekul ditentukan berdasarkan kerapatan elektron pada molekul tersebut (Fiolhais et al., 2003). Menurut teori Hohenberg-Kohn kerapatan elektron pada keadaaan dasar secara prinsip dapat digunakan untuk menghitung fungsi gelombang dari banyak partikel (Young, 2001). Keuntungan dari metode DFT adalah tidak terpengaruh oleh ukuran sistem, sehingga dapat digunakan untuk 
perhitungan sistim molekul yang kompleks dan hasil perhitunganya mendekati hasil eksperimen (Sousa et al., 2007).

Metode DFT ini telah diaplikasikan dalam beberapa hal, antara lain digunakan untuk meramalkan struktur elektronik, memprediksi energi dan geometri molekul (Li et al., 2003) mempelajari hubungan struktur molekul dengan kemampuan inhibisinya (Xia et al., 2008) dan menentukan interaksi molekul organik dengan permukaan logam (Ortega et al., 2007). Studi komputasi dengan metode DFT dapat digunakan untuk memperkirakan sifat antioksidan, (Samsonowicz and Regulska, 2017), sifat karsinogen (Fan et al., 2019), dye sensitizer (Pastore et al., 2010) dan inhibitor korosi (Gece and Bilgiç, 2017).

Penggunaan inhibitor merupakan salah satu metode yang paling praktis dan banyak digunakan untuk melindungi logam dari korosi (Efil et al., 2015). Inhibitor dapat membentuk lapisan teradsorpsi pada permukaan logam sehingga dapat memperlambat laju korosi (Arthur et al., 2019). Pada umumnya inhibitor korosi berasal dari senyawa organik dan anorganik (Quraishi and Khan, 2005).

Senyawa organik merupakan inhibitor korosi yang paling efisien, khususnya senyawa organik yang memiliki gugus fungsi bersifat elektronegatif dan elektron $\pi$ dalam ikatan rangkap dua atau tiga terkonjugasi (Ju et al., 2008), serta senyawa organik yang memiliki gugus heteroatom $(\mathrm{N}, \mathrm{O}, \mathrm{P}, \mathrm{S})$ dan atomatom dengan pasangan elektron bebas efektif sebagai inhibitor korosi (Udhayakalaa et al., 2014). Molekul inhibitor dengan gugus fungsi yang sesuai dapat teradsorpsi secara kimia (chemisorption) dengan pembentukan kompleks dan secara fisika (physisorption) dengan membentuk ikatan elektrostatik (Ju et al., 2008). Adsorpsi inhibitor selain dipengaruhi oleh struktur molekul inhibitor (Ju et al., 2008), juga dipengaruhi oleh faktor sterik, aromatis, kerapatan elektron pada atom donor serta dengan adanya gugus fungsi seperti $\mathrm{C}=\mathrm{NH}$, -N = N-, -CHO, R-OH, C = C, dan lainnya (Zaafarany and Abdallah, 2010).

Upaya untuk mendapatkan inhibitor yang ramah lingkungan telah banyak dilakukan, seperti penggunaan bahan alam dari tumbuh-tumbuhan seperti ekstrak kulit Gnetum gnemon. L (Emriadi et al., 2018), daun Theobroma cacao (Yetri et al., 2017), ekstrak daun Dodonaea viscosa (L.) (Gusti et al., 2016) dan ekstrak daun Toona sinensis (Emriadi et al., 2016).

Ammi visnaga merupakan tanaman dari family Apiaceae (Umbelliferae) yang di dalamnya terkandung senyawa metabolit sekunder yaitu khellin dan visnagin. Senyawa khellin dan visnagin pernah dilakukan uji inhibisi korosi secara ekperimen oleh El-Etre (2006). Kedua senyawa ini dilaporkan efektif sebagai inhibitor korosi, akan tetapi secara teoritis kedua senyawa ini belum pernah diteliti. Penentuan efisiensi inhibisi molekul khellin dan visnagin dapat dilakukan dengan program Gaussian, seperti yang telah dilakukan oleh beberapa peneliti sebelumnya (Khaled, 2010; Samuelson, 2015).
Tujuan dari penelitian ini adalah untuk memperluas pemahaman terhadap efisiensi inhibisi molekul khellin dan visnagin dengan metode DFT serta untuk menentukan hubungan antara struktur molekul dengan inhibisi korosi melalui parameter kimia kuantum. Parameter yang dihitung $\mathrm{E}_{\text {Hомо }}$ (Highest Occupied Molecular Orbital), energi $\mathrm{E}_{\mathrm{LumO}}$ (Lowest Uncoppied Molecular Orbital), energi celah ( E), afinitas elektron (A), potensial ionisasi (I) momen dipol ( ), energi total $\left(\mathrm{E}_{\mathrm{T}}\right)$, global hardness $(\eta)$, global softness $(\sigma)$, elektronegativitas $(\chi)$, elektrofilisitas $(\omega)$, elektron transfer dari molekul inhibitor dengan logam besi ( $N$ ) dan Energi interaksi (Eint).

\section{Metode}

\subsection{Struktur molekul}

Struktur molekul khellin dan visnagin diperoleh dari literatur untuk analisis dengan metode DFT. Struktur 3Dimensi (3D) molekul khellin dan visnagin diambil dari struktur database dan dioptimalkan dengan metode DFT. Gambar 1, dioptimasi sebagai file input studi perhitungan parameter kimia kuantum.

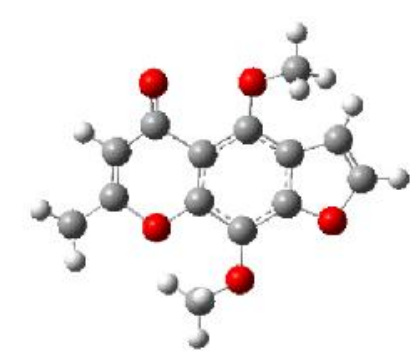

a)

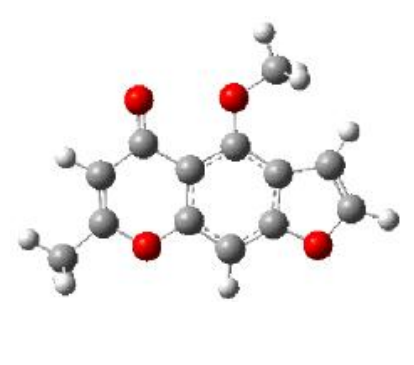

b)
Gambar 1 Struktur 3D a) Khellin dan b) Visnagin (atom: putih=H (ukuran atom lebih kecil); merah=O; abu$\mathrm{abu}=\mathrm{C})$.

\subsection{Software}

Perhitungan molekul Khellin dan Visnagin dilakukan dengan perangkat lunak Gaussian 16, menggunakan metode DFT dengan tiga parameter fungsional hybrid pertukaran dan korelasi Beck, Lee-Yang-Parr (B3LYP) set basis 6-31G (d, p). Sifat elektronik inhibitor dipelajari dengan menghitung pengaruh dari fungsi energi orbital molekul HOMO, LUMO, energi celah ( $\mathrm{E}$ $\left.=\mathrm{E}_{\text {LUMO }}-\mathrm{E}_{\mathrm{HOMO}}\right)$ momen dipol dan parameter lainya terhadap inhibisi korosi molekul inhibitor. Setelah diperoleh molekul yang optimal, selanjutnya dilakukan optimasi kembali dengan atom Fe untuk menentukan posisi interaksi yang paling stabil.

\subsection{Detail perhitungan kimia kuantum}

Secara teoritis perhitungan potensial ionisasi (I) dan afinitas elektron (A) menggunakan teorema yang dikembangkan oleh Koopman (1934) dalam Pain (2011), dimana menjelaskan bahwa hubungan antara potensial ionisasi (I), afinitas elektron (A) dan energi orbital 
( $\mathrm{E}_{\text {Hомо }}$ dan $\mathrm{E}_{\mathrm{LUMO}}$ ) seperti persamaan (1) dan (2) sebagai berikut:

$$
\begin{aligned}
& I=-E_{\text {HOMO }} \\
& A=-E_{\text {LUMO }}
\end{aligned}
$$

Orbital molekul HOMO dan LUMO berhubungan dengan kemampuan reaktif dari inhibitor. Energi celah $(\Delta \mathrm{E})$ merupakan fungsi reaktivitas molekul inhibitor yang teradsorpsi pada permukaan logam (Gece and Bilgiç, 2010). $\Delta \mathrm{E}$ dapat diperoleh dengan persamaan (3):

$$
\text { Energi celah }(\mathrm{E})=\mathrm{E}_{\mathrm{LUMO}}-\mathrm{E}_{\mathrm{HOMO}}
$$

Dalam aplikasi numerik, potensi kimia momen dipol ( ) dan global hardness ( $\eta$ ) diperoleh dari perhitungan potensi ionisasi (I) dan afinitas elektron (A). Elektronegativitas adalah ukuran kekuatan elektron atau sekelompok atom untuk menarik elektron ke arahnya (Pauling, 1960). Persamaan elektronegativitas $(\chi)$ seperti persamaan (4) sebagai berikut:

$$
x=\frac{I+A}{2}
$$

Global hardness ( $\eta$ ) mengukur resistensi sebuah atom untuk transfer muatan, sedangkan global softness merupakan polarizabilitas elektron yang menggambarkan kapasitas suatu atom atau kelompok atom untuk menerima elektron (Eddy, 2011) seperti persamaan (5) sebagai berikut:

$$
\eta=\underset{2}{\mathrm{I}-\mathrm{A}}
$$

Parameter global softness ( $\sigma)$ kebalikan dari global hardness ( $\eta$ ) dengan persamaan (6) seperti di bawah ini:

$$
0=\frac{1}{\eta}
$$

Elektrofilisitas diperkenalkan oleh Parr et al. (1999) merupakan deskriptor reaktivitas secara kuantitatif berhubungan dengan sifat elektrofilik suatu molekul dalam skala relatif. Parr mengusulkan bahwa elektrofilisitas $(\omega)$ sebagai ukuran energi minimum dengan elektron maksimum yang dialirkan antara donor dan akseptor elektron. Persamaan (7) untuk menentukan nilai elektrofilisitas $(\omega)$ sebagai berikut:

$$
\omega=\frac{\mu 2}{2}
$$

Perpindahan elektron terjadi dari molekul dengan elektronegativitas yang lebih rendah (inhibitor organik) ke elektronegativitas yang lebih tinggi (permukaan logam) hingga potensialnya menjadi sama. Oleh karena itu transfer elektron $\mathrm{N}$ dari molekul inhibitor ke permukaan logam dihitung menggunakan nilai elektronegativitas (Pearson, 1988) dengan persamaan (8) seperti dibawah ini:

$$
\Delta N=\frac{\chi_{F:}-\chi_{\text {in }}}{2\left(\eta_{F:}+\eta_{\text {int }}\right)}
$$

$\chi_{\mathrm{Fe}}$ adalah elektronegativitas logam $\mathrm{Fe}$ dan $\chi_{\text {inh }}$ elektronegativitas molekul inhibitor; $\eta_{\mathrm{Fe}}$ dan $\eta_{\text {inh }}$ menunjukkan kekerasan absolut logam Fe dan molekul inhibitor. Nilai teoritis $\chi_{\mathrm{Fe}}=7 \mathrm{eV}$ dan $\eta_{\mathrm{Fe}}=0$ digunakan untuk perhitungan nilai $\mathrm{N}$ (Pearson, 1988).

Penentuan energi interaksi $\left(\mathrm{E}_{\text {interaksi }}\right)$ molekul inhibitor pada permukaan logam besi (Xia et al., 2008) sebagai berikut :

$$
\mathrm{E}_{\text {interaksi }}=\mathrm{E}_{\text {Total })}-\mathrm{E}_{\mathrm{Fe}}-\mathrm{E}_{\text {inhibitor }}
$$

$\mathrm{E}_{\text {interaksi }}$ adalah energi interaksi, Etotal adalah energi kristal Fe yang teradsorbsi dengan molekul inhibitor, $\mathrm{E}_{\mathrm{Fe}}$ dan $E_{\text {inhibitor }}$ adalah energi total krital Fe dan energi total dari inhibitor. Nilai $E_{\text {binding }}$ dapat diperoleh dari persamaan (10) seperti di bawah ini:

$$
\mathrm{E}_{\text {binding }}=-\mathrm{E}_{\text {interaksi }}
$$

Energi binding merupakan nilai negatif dari energi interaksi. Persamaan ini dapat menentukan proses reaksi yang terjadi.

\section{Hasil dan pembahasan \\ 3.1. Parameter kimia kuantum}

Khellin (4,9-Dimethoxy-7-methylfuro [3,2-g] chromen-5-one) dan Visnagin (4-Methoxy-7-methyl-5Hfuro [3,2-g] [1] benzopyran-5-one) merupakan senyawa organik turunan furanochromones dengan rumus molekul khelin $\mathrm{C}_{14} \mathrm{H}_{12} \mathrm{O}_{5}$ dan visnagin $\mathrm{C}_{13} \mathrm{H}_{10} \mathrm{O}_{4}$ (Gomes, 1956). Ekstrak biji Ammi visnaga efektif sebagai inhibitor korosi. Hal ini karena biji Ammi visnaga memiliki atom oksigen yang berfungsi sebagai pendonor elektron terhadap logam $\mathrm{Fe}^{2+}$ untuk membentuk senyawa kompleks (Maleck et al., 2013). Adsorpsi senyawa tersebut pada permukaan logam dapat menghalangi terjadinya transfer muatan dan massa sehingga menyebabkan penurunan interaksi logam dengan lingkungan korosif. Akibatnya, laju korosi dari logam berkurang (El-Etre, 2006).

Struktur inhibitor korosi secara langsung terkait dengan efisiensi adsorpsi terhadap logam dan menunjukkan pentingnya beberapa parameter kuantum seperti energi orbital molekul HOMO, LUMO, perbedaan energi $(\Delta \mathrm{E})$, muatan atom (Granese, 1988) dan momen dipol (Martinez, 2003).

Gambar 2 memperlihatkan distribusi kerapatan orbital molekul khellin dan visnagin yang diperoleh dengan metode DFT basis set B3LYP/6-31G (d, p) dengan program Gaussian. Dari gambar terlihat bahwa distribusi elektron pada molekul khellin dan visnagin pada daerah HOMO menunjukkan bahwa elektron terlokalisasi terutama pada cincin benzen, atom oksigen dan ikatan $\mathrm{C}=\mathrm{C}$ pada cincin furan. Bagian atom-atom ini diperkirakan menjadi pusat interaksi antara molekul inhibitor dengan permukaan logam. Atom-atom pada daerah HOMO ini berperan sebagai donor elektron dari molekul inhibitor dengan permukaan logam membentuk ikatan koordinasi.

Pada daerah LUMO dapat terlihat bahwa distribusi elektron pada molekul khellin dan visnagin menunjukkan bahwa elektron terlokalisasi pada ikatan 
rangkap oksigen, atom karbon cincin pyron dan furan, ikatan $\mathrm{C}-\mathrm{C}$, dan ikatan $\mathrm{C}=\mathrm{C}$. Atom-atom ini berperan dalam akseptor elektron dari orbital logam ke orbital molekul inhibitor, seperti yang dikemukakan oleh Gece and Bilgiç. (2017) bahwa adsorpsi molekul pada orbital HOMO dan LUMO memiliki kekuatan yang sebanding.

a)

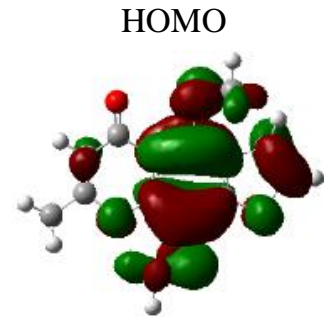

b)

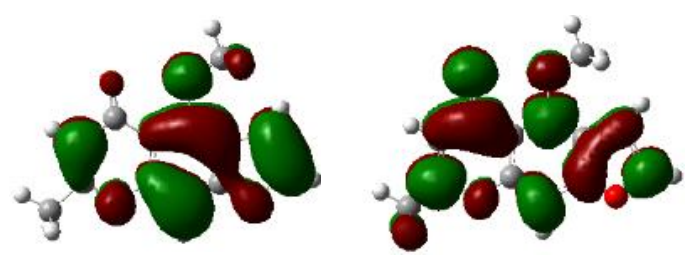

Gambar 2. Distribusi kerapatan orbital molekul; a) Khellin; b) Visnagin (atom : putih=H; merah=O; abu=C)

Dari hasil optimasi geometri senyawa visnagin dan khellin dengan metode DFT basis set B3LYP/6-31G (d, p) diperoleh nilai parameter kimia kuantum molekul visnagin dan khellin yang dapat dilihat pada Tabel 1 . Berdasarkan teori reaktifitas kimia orbital molekul, transisi elektron disebabkan oleh adanya interaksi antara orbital HOMO dan orbital LUMO dari suatu molekul. Energi HOMO berkaitan langsung dengan potensial ionisasi dan kerentanan molekul terhadap serangan elektrofil (Xia et al., 2008). Nilai $\mathrm{E}_{\text {Hомо yang tinggi }}$ menujukkan kemampuan inhibitor untuk menyumbangkan elektron ke permukaan logam. Nilai $\mathrm{E}_{\text {HOMO }}$ molekul khellin diperoleh lebih tinggi dari moleul visnagin yaitu $-0,2000 \mathrm{eV}$ sehingga molekul khellin lebih mudah terabsorbsi pada permukaan logam.

Nilai $\mathrm{E}_{\text {LUMO }}$ khellin lebih rendah dibandingkan dengan $\mathrm{E}_{\mathrm{LUMO}}$ visnagin. Hal ini menyebabkan kemampuan akseptor khellin lebih besar untuk menerima pasangan elektron bebas dari permukaan logam. Dengan membandingkan nilai $\mathrm{E}_{\mathrm{HOMO}}$ dan $\mathrm{E}_{\mathrm{LUMO}}$ dari visnagin dan khellin dapat diketahui bahwa khellin memiliki efisiensi inhibisi korosi yang lebih baik dibandingkan visnagin. Hal ini sesuai dengan yang dilaporkan oleh Gece and Bilgiç. (2017), bahwa semakin tinggi nilai $\mathrm{E}_{\mathrm{HOMO}}$ atau semakin rendah nilai $\mathrm{E}_{\mathrm{LUMO}}$ menandakan semakin kuat molekul organik untuk melekat pada kation logam sehingga molekul organik tersebut akan memiliki efisiensi inhibisi korosi yang tinggi (Gece and Bilgiç, 2012).

Tabel 1

Parameter kimia kuantum Khellin dan Visnagin

\begin{tabular}{|c|c|c|}
\hline Parameter & Khellin & Visnagin \\
\hline $\mathrm{E}_{\text {Номо }}(\mathrm{eV})$ & $-0,2000$ & $-0,2051$ \\
\hline $\mathrm{E}_{\text {LUMO }}(\mathrm{eV})$ & $-0,0381$ & $-0,0380$ \\
\hline Energi Celah / E (eV) & 0,1619 & 0,1671 \\
\hline Momen Dipol / (Debye) & 1,2947 & 2,9364 \\
\hline Potensial Ionisasi / I (eV) & 0,2000 & 0,2051 \\
\hline Afinitas Elektron / A (eV) & 0,0381 & 0,0380 \\
\hline Elektronegativitas / $\chi(\mathrm{eV})$ & $-0,1190$ & $-0,1218$ \\
\hline Global Hardness / $\eta(\mathrm{eV})$ & 0,0809 & 0,0832 \\
\hline Global Softness / $\sigma\left(\mathrm{eV}^{-1}\right)$ & 12,3586 & 12,0099 \\
\hline Elektroplicity / $\omega\left(\mathrm{D}^{2} / \mathrm{eV}\right)$ & 10,3580 & 51,7771 \\
\hline Transfer Elektron / N & 0,2965 & 0,2988 \\
\hline Massa Molekul (g/mol) & 260,245 & 230,219 \\
\hline Energi total (a.u) & $-916,6680$ & $-802,2806$ \\
\hline
\end{tabular}

Pada Tabel 1 dapat dilihat bahwa nilai $\Delta \mathrm{E}$ khellin yaitu $0,1619 \mathrm{eV}$ lebih rendah daripada nilai $\Delta \mathrm{E}$ visnagin yaitu $0,1671 \mathrm{eV}$. Hal ini menandakan bahwa khellin lebih efektif teradsorpsi pada permukaan logam dibandingkan visnagin, seperti yang dilaporkan oleh Udowo (2018) bahwa E yang yang lebih besar mengakibatkan molekul membutuhkan energi yang lebih besar juga untuk tereksitasi dari orbital HOMO ke orbital LUMO. Semakin rendah nilai $\Delta E$ suatu molekul maka semakin baik efisiensi inhibisi korosinya. Hal ini sesuai dengan yang telah dikemukakan oleh Ebenso et al. (2011).

Nilai potensial ionisasi khellin $(0,2000 \mathrm{eV})$ lebih rendah dibanding nilai potensial visnagin $(0,2051 \mathrm{eV})$. Nilai potensial ionisasi yang lebih rendah menunjukkan bahwa khellin bersifat lebih reaktif dibandingkan visnagin, sehingga khellin lebih mudah berikatan dengan permukaan logam. Molekul yang bersifat reaktif memiliki nilai potensial ionisasi yang rendah, seperti yang dikemukakan oleh Chakraborty et al. (2010).

Khellin juga memiliki nilai keelektronegatifan yang lebih besar yaitu $-0,1190 \mathrm{eV}$ dibandingkan dengan nilai keelektronegatifan visnagin yaitu $-0,1218 \mathrm{eV}$. Hal ini menandakan bahwa khellin memiliki kemampuan menarik elektron lebih tinggi dibanding visnagin, dan oleh sebab itu khellin merupakan inhibitor yang lebih baik dibanding visnagin, seperti yang dilaporkan oleh Udowo (2008) bahwa nilai keelektronegatifan yang besar menyebabkan molekul lebih mudah menarik elektron kearahnya sehingga lebih mudah teradsorpsi pada permukaan logam. 
Nilai global hardness khellin $(0,0809 \mathrm{eV})$ lebih rendah dibandingkan visnagin $(0,0832 \mathrm{eV})$, sementara nilai global softness khellin yaitu $12,3586 \mathrm{eV}^{-1}$ lebih tinggi dibandingkan nilai global softness visnagin yaitu $12,0099 \mathrm{eV}^{-1}$. Hal ini menunjukkan bahwa khellin adalah molekul yang bersifat global softness yang mudah bereaksi dan membentuk ikatan koordinasi dengan permukaan logam, sehingga dapat digunakan sebagai inhibitor korosi. Hal ini sesuai dengan yang dilaporkan oleh Pearson, (1988) bahwa molekul yang memiliki nilai global hardness lebih tinggi cenderung sulit bereaksi dengan permukaan logam, sedangkan molekul yang memiliki nilai global softness lebih tinggi menunjukkan sebaliknya.

Pada Tabel 1 dapat dilihat nilai elektron transfer $(\Delta N)$ dan berat molekul khellin lebih tinggi dibanding visnagin. Nilai elektron transfer yang tinggi pada molekul khellin yaitu 0,2965 menandakan bahwa khellin lebih mudah mendonorkan elektron ke permukaan logam, sehingga khellin lebih mudah teradsorbsi pada permukaan logam. Selama proses interaksi antara molekul inhibitor dengan permukaan logam, elektron akan berpindah dari molekul yang memiliki nilai keelektronegatifan kecil ke permukaan logam yang memiliki nilai keelektronegatifan yang lebih tinggi hingga terjadi kesetimbangan elektronegativitasnya, yang berkaitan dengan nilai transfer elektron pada molekul khellin. Gece and Bilgiç. (2017) mengemukakan bahwa jika $\mathrm{N}<3,6$ maka efisiensi inhibisi korosi meningkat dengan meningkatkan kemampuan donor elektron dari molekul untuk menyumbangkan elektron ke permukaan logam.

Nilai momen dipol ( ) khellin yaitu 1,2947 Debye lebih rendah dibandingkan momen dipol visnagin yaitu 2,9364 Debye. Nilai momen dipol yang lebih rendah meningkatkan adsorpsi inhibitor pada permukaan logam dan menyebabkan efisiensi inhibisi korosi menjadi lebih tinggi (Bouklah et al., 2012; Khalil, 2003), sementara itu beberapa peneliti menyatakan bahwa efisiensi inhibisi korosi meningkat dengan meningkatnya nilai momen dipol (Quraishi et al., 2003; Udhayakalaa et al., 2014). Berdasarkan survei literatur ditemukan beberapa penyimpangan dalam korelasi momen dipol dengan efisiensi inhibisi korosi (Bereket et al., 2002; Khaled et al., 2004).

Nilai elektrofilitas khellin $\left(10,3580 \quad \mathrm{D}^{2} / \mathrm{eV}\right)$ lebih rendah dibandingkan dengan nilai elektrofililitas visnagin $\left(51,7771 \mathrm{D}^{2} / \mathrm{eV}\right)$. Nilai elektrofililitas yang tinggi pada suatu molekul menunjukkan molekul tersebut sulit berikatan dengan permukaan logam besi. Jika nilai elektrofililitas molekul rendah maka molekul tesebut akan semakin mudah berikatan dengan permukaan logam besi. Hal ini menunjukkan bahwa khellin lebih mudah mengikat logam besi dibandingkan dengan visnagin.

Pada Tabel 1 dapat dilihat energi total khellin yaitu 916,6680 a.u lebih kecil dibandingkan dengan energi total visnagin yaitu $-802,280643$ a.u. Hal ini sesuai dengan yang dilaporkan oleh Arthur et al. (2019) bahwa semakin rendah nilai energi total suatu molekul maka akan semakin mudah molekul tersebut terserap pada permukaan logam dan molekul tersebut dapat digunakan sebagai inhibitor korosi.
Massa molekul khellin yaitu 260,246 g/mol yang lebih besar dari massa molekul visnagin yaitu 230,219 $\mathrm{g} / \mathrm{mol}$. Hal ini menandakan bahwa molekul khellin lebih baik dalam menutupi permukaan logam dikarenakan memiliki volume yang lebih besar yang dapat meningkatkan luas permukaan, seperti yang dilaporkan oleh Udowo (2018) bahwa berat molekul dapat mempengaruhi inhibisi korosi suatu molekul.

\subsection{Densitas muatan mulliken molekul khellin dan visnagin}

Nilai muatan mulliken senyawa visnagin dan khellin dapat dilihat pada Gambar 3. Muatan mulliken molekul visnagin dan khellin diperoleh dari hasil optimasi dengan metode DFT. Xia et al. (2008) mengemukakan bahwa semakin negatif muatan atom pada suatu molekul, maka atom tersebut dapat berperan sebagai pusat aktif yang akan berikatan dengan logam. Semakin negatif nilai muatannya maka akan semakin mudah terjadi donor elektron dari molekul inhibitor ke permukaan logam, sehingga kemampuan inhibisi suatu molekul inhibitor tergantung pada atom yang paling elektronegatif dalam struktur molekulnya.

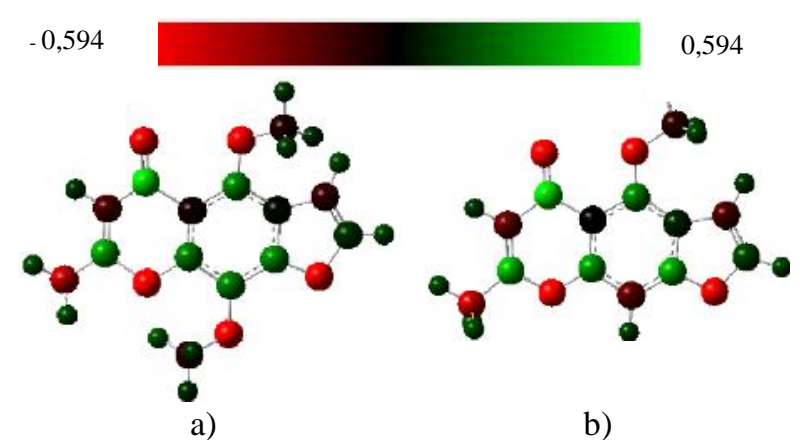

Gambar 3. Densitas muatan Mulliken molekul a) Khellin dan b) Visnagin

Pada Gambar 3 dapat dilihat bahwa densitas muatan Mulliken molekul khellin dan visnagin memiliki lebih dari satu pusat aktif yaitu pada atom oksigen dan beberapa atom karbon yang mempunyai kerapatan muatan elektron yang tinggi. Atom-atom ini berperan dalam interaksi antara inhibitor dengan permukaan logam. Khellin memiliki lebih banyak atom elektronegatif yang terdapat pada atom O27 dengan muatan -0,537130, atom O15 dengan muatan -0,527592 dan pada atom O16 dengan muatan -0,502790. Pada molekul visnagin kerapatan elektron tertinggi terdapat pada atom 016 dengan muatan $-0,533669$ dan pada atom O17 dengan muatan $-0,504495$. Atom O yang paling negatif pada khellin dan visnagin merupakan pusat aktif yang memiliki kemampuan paling kuat untuk berikatan dengan permukaan logam besi. Situs aktif pada molekul khellin lebih banyak dan lebih negatif dibandingkan dengan visnagin, sehingga dapat diketahui bahwa khellin lebih mudah mendonorkan elektron ke permukaan logam besi.

Beberapa atom $\mathrm{C}$ pada molekul khellin bermuatan positif yang merupakan sebagai pusat nukleofil yaitu pada atom C2 $(0,337525)$ dan pada C5 $(0,286861)$. Sedangkan pada visnagin muatan paling positif terdapat 
pada atom C2 $(0,418357)$ dan C5 $(0,336306)$. Melalui atom-atom tersebut molekul khellin dapat menerima pasangan elektron bebas dari logam besi, sehingga senyawa ini dapat berfungsi sebagai inhibitor korosi. Hal ini sesuai dengan yang dilaporkan oleh Obot et al. (2012) bahwa senyawa inhibitor korosi tidak hanya bersifat sebagai donor elektron pada permukaan logam, tetapi juga bersifat sebagai akseptor elektron dari permukaan logam.

\subsection{Absorbsi molekul khellin dan visnagin pada permukaan logam Fe}

Efek inhibisi korosi berasal dari proses adsorpsi inhibitor dengan permukaan logam, yaitu melalui pembentukan orbital atom antara molekul inhibitor dan logam. Hal ini sesuai dengan yang dikemukakan oleh Gece and Bilgiç. (2017). Untuk mengetahui proses adsorpsi antara molekul inhibitor dengan permukaan logam, maka dilakukan optimasi geometri molekul visnagin dan khellin dengan atom besi menggunakan metode DFT dengan program Gaussian yang dapat dilihat pada Gambar 4.

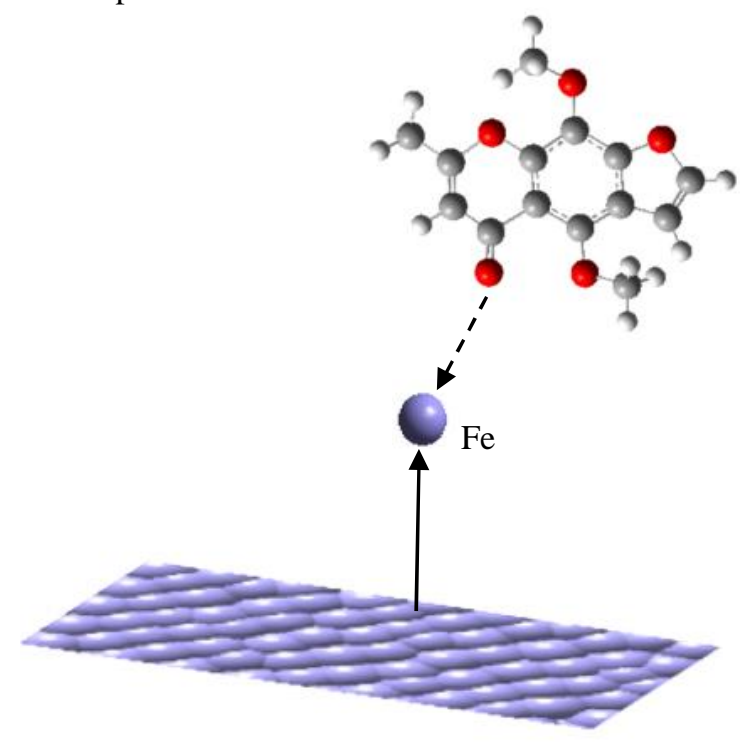

Gambar 4. Skema optimasi molekul khellin dengan permukaan logam besi

Pada Gambar 4 dapat dilihat mode skema perhitungan parameter kimia kuantum khellin pada permukaan besi, setelah diketahui sifat molekul visnagin dan khellin, dilanjutkan optimasi dengan penambahan logam besi pada setiap atom $\mathrm{O}$ dari kedua molekul tersebut. Tujuan optimasi dengan logam besi ini yaitu untuk menentukan posisi interaksi yang paling optimum antara kedua molekul tersebut dengan permukaan logam yang ditandai dengan nilai energi interaksi yang rendah seperti yang telah dilakukan oleh Şahin et al. (2008). Pada saat optimasi digunakan satu atom besi dan bukan permukaan besi untuk menyederhanakan perhitungan dan telah disepakati dalam literatur yang dilaporkan oleh Turcio (2007).

Saat optimasi digunakan satu atom $\mathrm{Fe}$ dan bukan permukaan $\mathrm{Fe}$, hal ini untuk menyederhanakan perhitungan dan telah disepakati dalam literatur (Ortega et al., 2007). Pada penelitian ini ditemukan bahwa molekul khellin terhubung dengan atom Fe melalui atom oksigen pada cincin pyron dan cincin benzen yang membentuk kompleks khelat ditunjukan oleh Gambar 5.

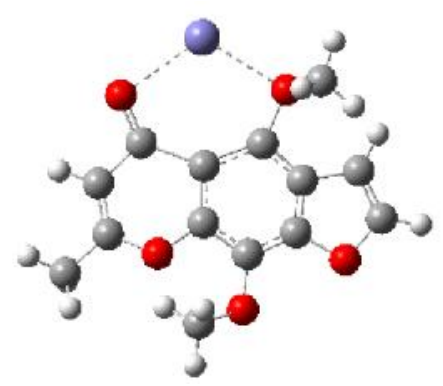

Gambar 5. Optimasi kompleks molekul khellin dan atom $\mathrm{Fe}$

Pada Gambar 5 terlihat bahwa optimasi paling optimum antara molekul khellin dan pemukaan logam besi dapat membentuk kompleks khelat oleh dua gugus metoksi yang berdekatan dari molekul khellin. Hasil ini sesuai dengan ekperimen yang telah dilakukan oleh ElEtre (2006) tentang mekanisme inhibisi korosi senyawa visnagin dan khellin dapat membentuk senyawa kompleks saat berinteraksi dengan permukaan logam, sehingga proses adsorbsi yang terjadi pada molekul visnagin dan khellin adalah adsorpsi kimia. Hal ini disebabkan oleh terjadinya transfer muatan melalui pasangan elektron bebas dari atom $\mathrm{O}$ pada molekul visnagin dan khellin dengan permukaan logam besi yang membentuk ikatan koordinasi.

Menurut Zor et al. (2009) inhibitor tidak mungkin teradsorpsi secara keseluruhan menutupi permukaan logam, tetapi dapat menempati pusat aktif dengan mengurangi laju reaksi anodik atau katodik, sehingga laju korosi akan menurun selama situs aktif tertutupi oleh inhibitor yang teradsorpsi.

Hasil optimasi lanjutan molekul visnagin dan khellin dengan atom $\mathrm{Fe}$ diperoleh energi kompleks $\left(\mathrm{E}_{\mathrm{Fe} \text {-inhibitor }}\right)$ pada setiap atom $\mathrm{O}$ dari molekul tersebut. Energi kompleks ini berguna untuk menentukan nilai Energi interaksi $\left(\mathrm{E}_{\mathrm{int}}\right)$ antara molekul visnagin dan khellin dengan permukaan atom besi, karena interaksi antara molekul inhibitor dengan permukaan logam besi sangat penting untuk memahami proses inhibisi korosi.

Energi interaksi $\left(E_{\text {int }}\right)$ dan Energi ikatan ( $\left.E_{\text {binding }}\right)$ molekul khellin dan visnagin dihitung dengan persamaan (9 dan 10). Energi ini sangat perlu diketahui untuk menjelaskan tentang interaksi yang terjadi antara molekul yang teradsorpsi dan permukaan logam. Hasil perhitungan yang diperoleh menujukan bahwa nilai $\mathrm{E}_{\text {interaksi }}$ molekul khellin yaitu $-5,1701$ (a.u) lebih rendah dibanding $E_{\text {interaksi }}$ molekul visnagin yaitu -5,1473 (a.u).

Nilai $E_{\text {int }}$ negatif, yang berarti bahwa adsorpsi dapat terjadi secara spontan pada permukaan logam Fe. Semakin negatif nilai $\mathrm{E}_{\text {int }}$ menandakan bahwa semakin efektif dan kuat interaksi yang terjadi antara molekul inhibitor dan permukaan logam (Nix, 2003), sehingga kompleks molekul yang terbentuk memiliki efisiensi inhibisi yang lebih tinggi. Selain itu energi ikatan yang diperoleh dari molekul khellin yaitu 5,1701 (a.u) lebih tinggi dibanding molekul visnagin yaitu 5,1473 a.u, 
besarnya energi binding menunjukkan bahwa inhibitor teradsorpsi pada lebih dari satu pusat adsorpsi (Şahin et al., 2008).

\section{Kesimpulan}

Dari hasil perhitungan kimia kuantum menggunakan metode DFT dengan basis set-B3LYP/6-311G (d,p) diperoleh korelasi inhibisi korosi dengan parameter elektronik senyawa khellin dan visnagin. Energi HOMO, LUMO dan energi celah ( E) menunjukkan molekul khellin lebih baik sebagai inhibitor korosi dibandingkan molekul visnagin. Parameter lainnya seperti global hardness ( $\eta$ ), global softness ( $\sigma)$, momen dipol ( ), potensial ionisasi (I), afinitas elektron (A), elektronegativitas $(\chi)$, elektron transfer ( $\mathrm{N}$ ), energi total $\left(E_{T}\right)$, energi interaksi $\left(E_{\text {int }}\right)$, dan berat molekul $(\mathrm{m} / \mathrm{g})$ menunjukkan efisiensi inhibisi molekul khellin yang tinggi dan hasil ini mendukung studi ekeperimen yang telah dilakukan oleh peneliti sebelumnya.

Molekul khellin yang berikatan dengan permukaan logam besi membentuk kompleks khelat, yaitu diantara dua gugus metoksi yang saling berdekatan pada struktur molekul khellin. Energi interaksi khellin yaitu -5,1701 a.u menandakan bahwa terjadi proses adsorpsi kimia dan berlangsung secara spontan.

\section{Daftar pustaka}

Arthur, D.E., Uzairu, A., Mustapha, A., Adeniji, E.S., 2019. A computational adsorption and DFT studies on corrosion inhibition potential of some derivatives of phenyl-urea. Kenkyu J. Nanotechnol. Nanosci. 5, 19-32.

Bereket, G., Hu, E., 2002. Quantum chemical studies on some imidazole derivatives as corrosion inhibitors for iron in acidic medium. J. Mol. Struct. 578, 79-88.

Bouklah, M., Harek, H., Touzani, R., Hammouti, B., Harek, Y., 2012. DFT and quantum chemical investigation of molecular properties of substituted pyrrolidinones. Arab. J. Chem. 5, 163-166. https://doi.org/10.1016/j.arabjc.2010.08.008

Chakraborty, S., Zhang, J., Krause, J.A., Guan, H., 2010. An efficient nickel catalyst for the reduction of carbon dioxide with a borane. J. Am. Chem. Soc. 132, 8872-8873. https://doi.org/10.1021/ja103982t

Comba, P., Hambley, T.W., 2001. Molecular modeling of inorganic compounds. Wiley-VCH.

Ebenso, E.E., Arslan, T., Kandermili, F., Caner, N., Love, I., 2010. Quantum chemical studies of some rhodanine azosulpha drugs as corrosion inhibitors for mild steel in acidic medium. Mater. Chem. Phys. 110, 1003-1018. https://doi.org/10.1002/qua

Eddy, N.O., 2011. Experimental and theoretical studies on some amino acids and their potential activity as inhibitors for the corrosion of mild steel, part 2. J. Adv. Res. 2, 35-47. https://doi.org/10.1016/j.jare. 2010.08.005

Efil, Kürşat; Bekdemir, Y., 2015. Theoretical study on corrosion inhibitory action of some aromatic imines with sulphanilic acid: A DFT study. Can. Chem. Trans. 3, 85-93. https://doi.org/10.13179/ canchemtrans.2015.03.01.0165
El-Etre, A.Y., 2006. Khillah extract as inhibitor for acid corrosion of SX 316 steel. Appl. Surf. Sci. 252, 8521-8525. https://doi.org/10.1016/j.apsusc.2005.11. 066

Emriadi, Santoni, A., Stiadi, Y., 2016. Adsorptive and thermodynamic properties of methanol extract of Toona sinensis leaves for the corrosion of mild steel in $\mathrm{HCl}$ medium. Der Pharma Chem. 8, 266-273.

Emriadi, Yulistia, V., Aziz, H., 2018. Corrosion inhibition of mild steel in hidrochloric acid solution by Gnetum gnemon. L peel extract as green inhibitor. Der Pharma Chem. 10, 79-85.

Fan, T., Sun, G., Zhao, L., Cui, X., Zhong, R., 2019. Metabolic activation and carcinogenesis of tobaccospecific nitrosamine N'-nitrosonornicotine (NNN): A density function theory and molecular docking study. Int. J. Environ. Res. Public Health 16, 1-20. https://doi.org/10.3390/ijerph16020178

Fiolhais C., Nogueira F., Marques, M., (Eds), 2003. A Primer in Density Functional Theory, Springer. Springer, Coimbra. https://doi.org/10.1017/ CBO9781107415324.004

Gece, G., 2017. Theoretical basis for the corrosion inhibition feature of Argan oil. Bulg. Chem. Commun. 49, 846-851.

Gece, G., Bilgiç, S., 2017. A computational study of two hexitol borates as corrosion inhibitors for steel. Int. J. Corros. Scale Inhib. 6, 476-484. https://doi.org/10.17675/2305-6894-2017-6-4-7

Gece, G., Bilgiç, S., 2012. Molecular-level understanding of the inhibition efficiency of some inhibitors of zinc corrosion by quantum chemical approach. Ind. Eng. Chem. Res. 51, 14115-14120. https://doi.org/10.1021/ie302324b

Gece, G., Bilgiç, S., 2010. A theoretical study on the inhibition efficiencies of some amino acids as corrosion inhibitors of nickel. Corros. Sci. 52, 34353443. https://doi.org/10.1016/j.corsci.2010.06.015

Granese, S.L., 1988. Study of the inhibitory action of nitrogen-containing compounds. Corrosion 44, 322327. https://doi.org/10.5006/1.3583944

Gusti, D.R., Emriadi, Alif, A., Efdi, M., 2016. Surface characteristics on mild steel using aqueous extract of cassava (Manihot esculenta) leaves as a corrosion inhibitor. Der Pharma Chem. 8, 113-118.

Ju, H., Kai, Z.P., Li, Y., 2008. Aminic nitrogen-bearing polydentate Schiff base compounds as corrosion inhibitors for iron in acidic media: A quantum chemical calculation. Corros. Sci. 50, 865-871. https://doi.org/10.1016/j.corsci.2007.10.009

Khaled, K.F., 2010. Corrosion control of copper in nitric acid solutions using some amino acids - A combined experimental and theoretical study. Corros. Sci. 52, 3225-3234. https://doi.org/10.1016/j.corsci.2010. 05.039

Khaled, K.F., Babic-Samardzija, K., Hackerman, N., 2004. Theoretical study of the structural effects of polymethylene amines on corrosion inhibition of iron in acid solutions. Electrochim. Acta 50, 2515-2520. https://doi.org/10.1016/j.electacta.2004.10.079

Khalil, N., 2003. Quantum chemical approach of corrosion inhibition. Electrochim. Acta 48, 26352640. https://doi.org/10.1016/S0013-4686(03) 
00307-4

Li, X., Sevilla, M.D., Sanche, L., 2003. DFT investigation of dehalogenation of adenine-halouracil base pairs upon low-energy electron attachment. J. Am. Chem. Soc. 125, 8916-8920. https://doi.org/10.1021/ja034286u

Maleck, M., Serdeiro, M., Carvalho dos Santos, F., de Almeida, A., Ferreira, B., Guimarães, A., Gunaydin, K., 2013. Khellin: A furanochromone with toxicity against Oncopeltus fasciatus (Hemiptera) and Aedes aegypti (Diptera). J. Nat. Pharm. 4, 32. https://doi.org/10.4103/2229-5119.110348

Martinez, S., 2003. Inhibitory mechanism of mimosa tannin using molecular modeling and substitutional adsorption isotherms. Mater. Chem. Phys. 77, 97102. https://doi.org/10.1016/S0254-0584(01)00569-7

Nix, R., 2003. An introduction to surface chemistry. Queen Mary University of London, London.

Obot, I.B., Ebenso, E.E., Akpan, I.A., Gasem, Z.M., Afolabi, A.S., 2012. Thermodynamic and density functional theory investigation of sulphathiazole as green corrosion inhibitor at mild steel/Hydrochloric acid interface. Int. J. Electrochem. Sci. 7, 1978-1996.

Ortega, T, D., Pandiyan, T., Cruz, J., Garcia-Ochoa, E., 2007. Interaction of imidazoline compounds with Fen (n ) 1-4 Atoms) as a model for corrosion inhibition: DFT and electrochemical studies D. J. Phys. Chem. C 111, 9853-9866.

Pain, J.C., 2011. Koopmans' theorem in the statistical Hartree-Fock theory. J. Phys. B At. Mol. Opt. Phys. 44.https://doi.org/10.1088/0953-4075/44/14/145001

Parr, R.G., Szentpály, L. V., Liu, S., 1999. Electrophilicity index. J. Am. Chem. Soc. 121, 19221924. https://doi.org/10.1021/ja983494x

Pastore, M., Angelis, F. De, Cnr, I., 2010. Aggregation of organic dyes on $\mathrm{TiO} 2$ in. ACS Nano 4, 556-562. https://doi.org/10.1021/nn901518s

Pauling, L., 1960. The nature of the chemical bond. Cornell University Press, Ithaca, New York. https://doi.org/10.1086/286682

Pearson, R.G., 1988. Absolute electronegativity and hardness: application to inorganic chemistry. Inorg. Chem. 27, 734-740. https://doi.org/10.1021/ ic00277a030

Prianto, B., 2007. Pemodelan kimia komputasi. Ber. Dirgant. 8, 4.

Quraishi, M.., Khan, S., 2005. Thiadiazoles-a potential class of heterocyclic inhibitors for prevention of mild steel corrosion in hydrochloric acid solution. Indian J. Chem. Technol. 12, 576-581.

Quraishi, M.A., Sardar, R., 2003. Hector bases - a new class of heterocyclic corrosion inhibitors for mild steel in acid solutions. J. Appl. Electrochem. 33,
$1163-1168$

Şahin, M., Gece, G., Karcı, F., Bilgiç, S., 2008. Experimental and theoretical study of the effect of some heterocyclic compounds on the corrosion of low carbon steel in $3.5 \% \mathrm{NaCl}$ medium. J. Appl. Electrochem. 38, 809-815.https://doi.org/10.1007/ s10800-008-9517-3

Samsonowicz, M., Regulska, E., 2017. Spectroscopic study of molecular structure, antioxidant activity and biological effects of metal hydroxyflavonol complexes. Spectrochim. Acta - Part A Mol. Biomol. Spectrosc. 173, 757-771. https://doi.org/10.1016/ j.saa.2016.10.031

Samuelson, P.A., 2015. Proof that properly anticipated prices fluctuate randomly. LA Trobe University, Los Angles, pp. 25-38. https://doi.org/10.1142/ 9789814566926_0002

Sousa, S.F., Fernandes, P.A., Ramos, M.J., 2007. General performance of density functionals. J. Phys. Chem. A 111, 10439-10452.

Udhayakalaa, P.; Rajendiranb , T. V.; Gunasekaranc, S., 2014. Theoretical approach to the corrosion inhibition efficiency of some pyrimidine derivatives using DFT method of mild steel in $\mathrm{HCl}$ solution. J. Chem. Pharm. Res. 6, 1216-1224.

Udowo, V., 2018. Computational studies of the corrosion inhibition potentials of quercetin and coumarin. Arch. Org. Inorg. Chem. Sci. 2, 168-171. https://doi.org/10.32474/aoics.2018.02.000133

Xia, S., Qiu, M., Yu, L., Liu, F., Zhao, H., 2008. Molecular dynamics and density functional theory study on relationship between structure of imidazoline derivatives and inhibition performance. Corros. Sci. 50, 2021-2029. https://doi.org/10.1016/ j.corsci.2008.04.021

Yetri, Y., Gunawarman, Emriadi, Novesar, J., 2017. Theobroma cacao extract peels (TCPE) green inhibitor to recovery the mechanical properties of mild steel after corrosion. ARPN J. Eng. Appl. Sci. 12, 5325-5332.

Young, D.C., 2001. Computational chemistry: A practical guide for applying techniques to real world problems. John Wiley \& Sons, Inc.

Zaafarany, I., Abdallah, M., 2010. Ethoxylated fatty amide as corrosion inhibitors for carbon steel in hydrochloric acid solution. Int. J. Electrochem. Sci. 5, $18-28$.

Zor, S., Kandemirli, F., Bingul, M., 2009. Inhibition effects of methionine and tyrosine on corrosion of iron in $\mathrm{HCl}$ solution: Electrochemical, FTIR, and quantum-chemical study. Prot. Met. Phys. Chem. Surfaces 45, 46-53. https://doi.org/10.1134/ s2070205109010079 